\title{
Behavioral and Neurobiological Effects of Deep Brain Stimulation in a Mouse Model of High Anxiety- and Depression-Like Behavior
}

\author{
Claudia Schmuckermair ${ }^{1,3}$, Stefano Gaburro',3, Anupam Sah', Rainer Landgraf', Simone B Sartori*,' and \\ Nicolas Singewald*,1 \\ 'Department of Pharmacology and Toxicology, Institute of Pharmacy and CMBI, Leopold-Franzens-University of Innsbruck, Innsbruck, Austria; \\ ${ }^{2}$ Max Planck Institute of Psychiatry, Munich, Germany
}

\begin{abstract}
Increasing evidence suggests that high-frequency deep brain stimulation of the nucleus accumbens (NAcb-DBS) may represent a novel therapeutic strategy for individuals suffering from treatment-resistant depression, although the underlying mechanisms of action remain largely unknown. In this study, using a unique mouse model of enhanced depression- and anxiety-like behavior (HAB), we investigated behavioral and neurobiological effects of NAcb-DBS. HAB mice either underwent chronic treatment with one of three different selective serotonin reuptake inhibitors (SSRIs) or received NAcb-DBS for I h per day for 7 consecutive days. Animals were tested in established paradigms revealing depression- and anxiety-related behaviors. The enhanced depression-like behavior of HAB mice was not influenced by chronic SSRI treatment. In contrast, repeated, but not single, NAcb-DBS induced robust antidepressant and anxiolytic responses in $\mathrm{HAB}$ animals, while these behaviors remained unaffected in normal depression/anxiety animals (NAB), suggesting a preferential effect of NAcb-DBS on pathophysiologically deranged systems. NAcb-DBS caused a modulation of challenge-induced activity in various stressand depression-related brain regions, including an increase in c-Fos expression in the dentate gyrus of the hippocampus and enhanced hippocampal neurogenesis in HABs. Taken together, these findings show that the normalization of the pathophysiologically enhanced, SSRI-insensitive depression-like behavior by repeated NAcb-DBS was associated with the reversal of reported aberrant brain activity and impaired adult neurogenesis in HAB mice, indicating that NAcb-DBS affects neuronal activity as well as plasticity in a defined, moodassociated network. Thus, HAB mice may represent a clinically relevant model for elucidating the neurobiological correlates of NAcb-DBS.

Neuropsychopharmacology (2013) 38, 1234-1244; doi: I0.1038/npp.2013.21; published online 6 February 2013
\end{abstract}

Keywords: treatment-resistant depression; antidepressant; neurogenesis; deep brain stimulation; nucleus accumbens; c-Fos

\section{INTRODUCTION}

Major depression is a highly debilitating and life-threatening disorder with a lifetime prevalence of $16.5 \%$ (Kessler et al, 2005) affecting $6.9 \%$ of the population every year (Wittchen et al, 2011). Available treatments include pharmacological approaches targeting mainly monoaminergic systems and non-pharmacological treatments, including psychotherapy, vagus nerve stimulation, transcranial magnetic stimulation, and electroconvulsive treatment (Moreines et al, 2011). Nevertheless, a significant number of patients remains inadequately treated displaying

*Correspondence: Dr SB Sartori or Professor N Singewald, Department of Pharmacology and Toxicology, Institute of Pharmacy and Centre for Molecular Biosciences Innsbruck (CMBI), Leopold-FranzensUniversity of Innsbruck, Innrain 80-82, Innsbruck 6020, Austria, Tel: + 43512507 58803, Fax: +43 512507 58889, E-mail: simone.sartori@uibk.ac.at or nicolas.singewald@uibk.ac.at

${ }^{3}$ The first two authors contributed equally to this work

Received 13 July 20 I2; revised I 8 December 20 I2; accepted 2 January 2013; accepted article preview online 16 January 2013 non-response or partial response after all treatment options have been explored (for a review see Al-Harbi, 2012; Vieta and Colom, 2011). This treatment-resistant depression (TRD) is particularly associated with great economic burden (Fostick et al, 2010), high social and familial impact (for a review see Luciano et al, 2012), and personal suffering. New hope is now given to these individuals by clinical studies demonstrating long-term effects of highfrequency deep brain stimulation (DBS) in terms of improving depressive symptoms of helplessness, anhedonia and anxiety, and, thus, enhancing quality of life (Bewernick et al, 2012; Lozano et al, 2012). Interestingly, physical and psychiatric side effects elicited by DBS can be minimized or abolished by adjustment of the stimulation settings (Bewernick et al, 2012) or, if unacceptable, DBS can be stopped at any time according to the basic principles of medical ethics and, in particular, those issues pertinent to DBS treatment (Schermer, 2011).

Although the ideal targets of DBS for eliciting therapeutic effects in TRD are a matter of debate (Lim et al, 2011), it has 
been suggested that any brain region of the proposed dysfunctional depression neurocircuitry (Krishnan and Nestler, 2008) may be interesting as affected network components are overlapping (Gutman et al, 2009). Accordingly, DBS has been applied to the subgenual cingulate cortex (Lozano et al, 2012), the ventral striatum (Malone et al, 2009), the nucleus accumbens (NAcb) (Bewernick et al, 2012), and the lateral habenula (Hoyer et al, 2012) of small TRD patient populations. Specifically, promising results have been obtained by DBS to the NAcb (NAcbDBS), which has induced solid antidepressant, anxiolytic, and antianhedonic effects in patients with TRD (Bewernick et al, 2012). The unique position of the NAcb in the brain enables it to act as a gateway for information being transmitted from emotional centers to motor control regions (Haber and Knutson, 2010). Functionally, the NAcb processes reward and pleasure information and is dysfunctional in patients suffering from depression (Tremblay et al, 2005). This is relevant, as anhedonia is one of the core symptoms of depression and reflects a lack of reward and reward-motivated behavior (Gorwood, 2008). The NAcb receives inputs from midbrain areas, such as the ventral tegmental area, the medial substantia nigra, the dorsal and medial raphe nuclei, the locus coeruleus, as well as from limbic structures, including the amygdala, the hippocampus (HPC), and the prefrontal cortex (Nauta and Domesick, 1984). In turn, it projects to cortical areas (including the infralimibic cortex and the orbitofrontal cortex (OFC)), and to the ventral pallidum, the thalamus, the amygdala, and the hypothalamus (Kelley and Stinus, 1984). Interestingly, as projections of the NAcb are glutamatergic as well as GABAergic, stimulation of the NAcb can modulate neuronal activity of emotion and motivation centers implicated in the pathophysiology of depression in a dual way (also see Schlaepfer et al, 2008).

The mechanisms through which DBS act are poorly understood (Kringelbach et al, 2010). While early observations in Parkinson patients led to the proposal of a functional block of the target region by DBS (Benabid et al, 2002), it is thought nowadays that DBS causes axonal activation and neuronal inhibition (Dostrovsky and Lozano, 2002; Vitek, 2002; see also McIntyre and Grill, 1999; Nowak and Bullier, 1998a, b). Therefore, clinically relevant animal models are pivotal to further study the neurobiological mechanisms underlying the beneficial effects of NAcb-DBS.

This study was aimed at providing the first comprehensive behavioral evaluation of NAcb-DBS in the HAB mouse line selectively bred for high trait anxiety (Landgraf et al, 2007; Sartori et al, 2011a). A characteristic comorbidity in $\mathrm{HAB}$ mice is the preference of immobility/passive stresscoping strategies, indicative of enhanced depression-related behavior reflecting depressive patients with comorbid anxiety. To gain insights into neurobiological mechanisms of action of successful NAcb-DBS treatment, we additionally studied stress-induced expression of the immediate-early gene c-Fos as the marker for neuronal activation, as well as a possible alteration of the amount of newly born cells and immature neurons in $\mathrm{HAB}$ mice. These sets of experiments were stimulated by studies showing that clinically established antidepressant drugs affect deranged bran activity patterns and adult hippocampal neurogenesis in humans and/or rodents (for a review see Samuels and Hen, 2011).

\section{MATERIALS AND METHODS}

\section{Animals}

Experiments were carried out on male (12-15 weeks old) $\mathrm{HAB}$ and normal depression/anxiety animals (NAB) mice bred for their innate level of anxiety-related behavior at the Department of Pharmacology and Toxicology (University of Innsbruck, Austria) (for details see Sartori et al, 2011a). Animals were group-housed under standard laboratory conditions (12:12 light/dark cycle with lights on at 07:00 hours, $22 \pm 2{ }^{\circ} \mathrm{C}, 50-60 \%$ humidity) with pelleted food and water available ad libitum. All experiments were designed to minimize animal suffering as well as the number of animals used. Experiments comprising this study were approved by the national ethical committee on animal care and use (Bundesministerium für Wissenschaft und Forschung) in compliance with international laws and policies.

\section{Drug Treatments}

Reboxetine (40 mg/kg per day; Ochem, Chicago, IL), desipramine $(30 \mathrm{mg} / \mathrm{kg}$ per day; Sigma-Aldrich, Vienna, Austria), fluoxetine (18 mg/kg per day; Eubio, Vienna, Austria), paroxetine (10 mg/kg per day; Ochem), and citalopram ( $10 \mathrm{mg} / \mathrm{kg}$ per day, kindly provided by Lundbeck, Denmark) were administered via the drinking water for 3 weeks. A drug intake of the dose indicated above was achieved by adapting the concentrations of the drug in the drinking solutions according to mean drinking volume and body weight per cage (Sartori et al, 2012). Mice were kept on drug treatment until completion of all experiments. Control mice received tap water. 5-Bromo-2'-deoxyuridine (BrdU) (Sigma-Aldrich) was injected at a dose of $100 \mathrm{mg} / \mathrm{kg}$ (intraperitoneally) once per day for 4 days for the labeling of newly born cells.

\section{Deep Brain Stimulation}

Before surgery, animals were handled for 3 days to habituate them to the experimenter and the stimulation procedure. Using a stereotaxic frame, anesthetized animals (ketamine/xylazine $80 / 5 \mathrm{mg} / \mathrm{kg}$, intraperitoneally) were implanted with electrodes (MS303-3-B-SPC, bipolar, twisted, $8 \mathrm{~mm}$; Plastics One, Roanoke, VA) reaching the NAcb core (coordinates: $1.10 \mathrm{~mm}$ anterior, $1.45 \mathrm{~mm}$ lateral, and $4.65 \mathrm{~mm}$ ventral to bregma). After surgery, animals were individually caged, and received buprenorphine $(0.1 \mathrm{mg} / \mathrm{kg}$ intraperitoneally) every $8 \mathrm{~h}$ over 3 days to minimize pain. Following 4-5 days of recovery, animals received highfrequency stimulations daily $(130 \mathrm{~Hz}, 100 \mu \mathrm{A}, 60 \mu$ s pulse width; A310 Accupulser and A365 Stimulus Isolator; World Precision Instruments, Berlin, Germany) for $1 \mathrm{~h}$ per day (NAcb-DBS). Control animals (NAcb-sham) were connected to the stimulator without current being applied. At the end of the experiments, localization of electrodes in the NAcb was confirmed on cresyl violet-stained coronal sections (see Figure 2b). Animals with misplaced electrodes were excluded from all data sets. 


\section{Experiments}

In Experiment 1, the sensitivity of $\mathrm{HAB}$ mice to the antidepressant efficacy of different selective serotonin reuptake inhibitors (SSRIs) was explored in the forced swim test (FST) (Figure 1). Experiments 2-4 (Figure 2a) were designed to investigate the effect of single and repeated NAcb-DBS (i) on the anxiety- and depression-related behavior displayed by $\mathrm{HAB}$ mice, using a battery of established tests, (ii) on adult hippocampal neurogenesis, and (iii) on challenge-induced neuronal activation patterns in different brain regions, using immunohistochemistry.

\section{Behavior}

All behavioral tests were performed on $\mathrm{HAB}$ and $\mathrm{NAB}$ mice $1 \mathrm{~h}$ after completion of NAcb-DBS or NAcb-sham. The FST and tail suspension test (TST) were used to assess depression-like behavior (for a review see Cryan and Mombereau, 2004; Cryan et al, 2005). Anxiety-related behavior was investigated using the novelty-suppressed feeding paradigm, while general locomotor activity was measured in the open field. All behavioral tests were performed according to previous protocols established in our laboratory (Sartori et al, 2012; Whittle et al, 2011), details of which are provided in the Supplementary Information.

\section{Immunohistochemistry}

At $2 \mathrm{~h}$ after the last challenge, when expression levels of c-Fos protein are at their peak (Zangenehpour and Chaudhuri, 2002), mice were deeply anesthetized with an overdose of sodium pentobarbital $(200 \mathrm{mg} / \mathrm{kg})$ and transcardially perfused with saline followed by $4 \%$ paraformaldehyde (in $0.1 \mathrm{~mol} / \mathrm{l}$ phosphate buffer, $\mathrm{pH}$ 7.4), as described

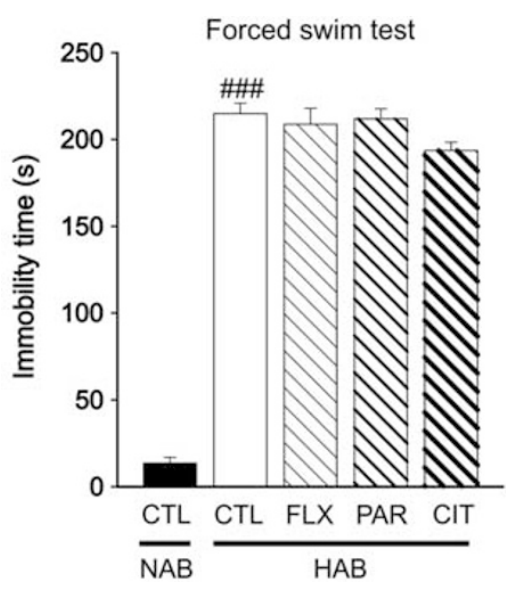

Figure I Sensitivity of high anxiety-related behavior ( $H A B$ ) mice to chronic treatment with selective-serotonin reuptake inhibitors. Relative to their normal depression/anxiety (NAB) counterparts, untreated HAB mice displayed enhanced depression-like behavior, as indicated by an increased period of immobility in the forced swim test. Chronic treatment with citalopram (CIT) (I $0 \mathrm{mg} / \mathrm{kg}$, per os), paroxetine (PAR) ( $10 \mathrm{mg} / \mathrm{kg}$, per os), or fluoxetine (FLX) ( $18 \mathrm{mg} / \mathrm{kg}$, per os) was not able to rescue the depressive phenotype of HABs. Data represent means \pm SEM. $N=8-10$ animals per group. ${ }^{\# \# P} P<0.00$ I for untreated control $(C T L) H A B$ vs untreated $C T L$ $\mathrm{NAB}$ mice. previously (Muigg et al, 2009). One-in-eight of the freefloating coronal sections $(50 \mu \mathrm{m})$ throughout the entire murine HPC were processed for BrdU, doublecortin (DCX), and c-Fos immunohistochemistry, respectively, following established protocols (Couillard-Despres et al, 2009; Muigg et al, 2009). Sections were incubated with one of the following primary antibodies: rat anti-BrdU $(1: 350$; Serotec, Dusseldorf, Germany), goat anti-DCX C18 (1:250; Santa Cruz Biotechnology, Santa Cruz, CA), rabbit anti c-Fos (1:10000; Santa Cruz Biotechnology). Subsequently, they were incubated with the corresponding biotinylated goat anti-rat, rabbit anti-goat, or goat anti-rabbit secondary antibody (all 1:200; Vector laboratories, Burlingame, CA). The formed antigen-antibody-complexes were visualized by the avidin-biotin-horseradish peroxidase procedure (Vectastain Elite ABC kit; Vector Laboratories) using $3,3^{\prime}$-diaminobenzidine as the chromogen.

Immunoreactive cells were quantified in the regions of interest using a light-optical microscope (Olympus, Vienna, Austria) and a computer-assisted image analysis system (cellSens Dimension; Olympus). A cell was considered as labeled (positive) for c-Fos, DCX, or BrdU when the brownblack DAB staining was unambiguously darker than the background, and this included all cells from low to high intensities of staining.

\section{Data Analysis}

Data are presented as mean \pm standard error of the mean (SEM). Exact $n$ numbers are given in the table and figure legends. Statistical analysis was performed using STATISTICA 8.0 (StatSoft, Tulsa, OK) after data had been screened for outliers using the Grubb's test. All data were further tested for homoscedasticity using Levene's test. Data were statistically analyzed using one-way ANOVA (post hoc Bonferroni) or unpaired Student's $t$-test. Statistical significance was set at $P<0.05$.

\section{RESULTS}

\section{HAB Mice Displayed Behavioral Insensitivity to SSRIs}

To investigate whether the $\mathrm{HAB}$ mouse model mimics features of treatment resistance, we first examined the efficacy of different classes of antidepressant drugs in reducing the enhanced depression-like behavior displayed by $\mathrm{HAB}$ mice in comparison with $\mathrm{NAB}$ mice. Reproducing our previous results (Sah et al, 2012), the immobility displayed in the FST was enhanced in $\mathrm{HAB}$ animals compared with their NAB counterparts. Chronic treatment with one of three SSRIs did not change the high immobility scores of male HAB mice in the FST $\left(\mathrm{F}_{4,31}=156.8, P<0.001\right.$; Figure 1). We observed that treatment resistance seemed to be restricted to drugs targeting solely the serotonergic system, as both the selective noradrenaline re-uptake inhibitor reboxetine and the tricyclic antidepressant desipramine significantly reduced the depression-like behavior of HAB mice assessed in the FST $\left(\mathrm{F}_{2,22}=8.761, P=0.002\right)$ (Supplementary Figure S1). 
a
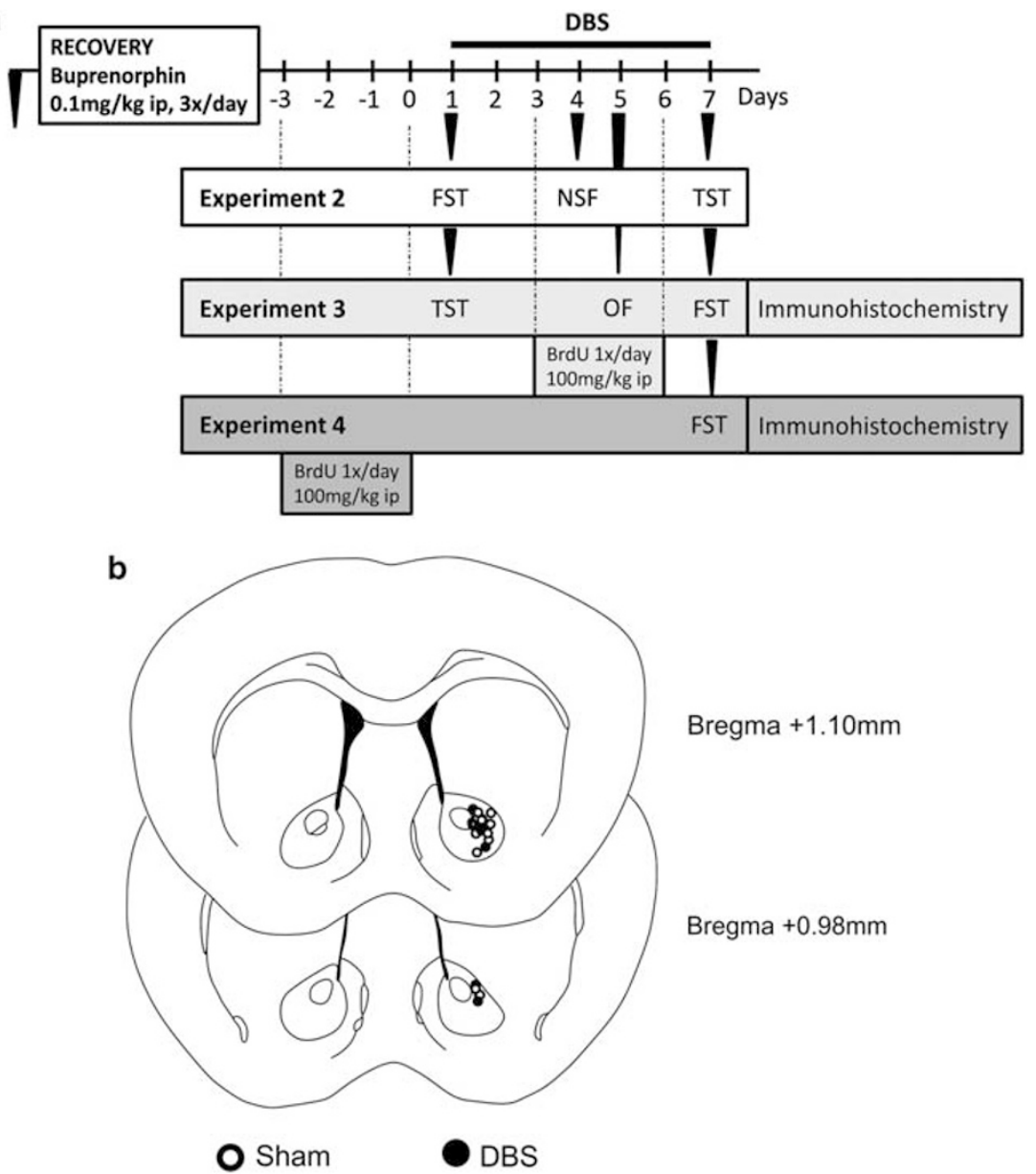

Figure 2 Experimental details of deep brain stimulation of the nucleus accumbens (NAcb-DBS) studies performed in high anxiety-related behavior (HAB) mice. (a) Timeline of NAcb-DBS experiments. Following surgery and recovery, NAcb-DBS was performed for I h per day for 7 consecutive days, whereas 5-bromo-2'-deoxyuridine (BrdU) was injected for 4 days. Effects of single and repeated $(7 \times)$ NAcb-DBS on depression- and anxiety-like behavior was assessed by forced-swim test (FST), tail suspension test (TST), and novelty suppressed feeding test (NSF). Locomotor activity was measured in the open field (OF). (b) Schematic figure (retrieved from Franklin and Paxinos, 2007) showing the localization of the electrode tips of all animals that participated in this study. Closed circles represent NAcb-DBS; open circles represent NAcb-sham animals.

NAcb-DBS Reduced Depression-Like Behavior in HAB, but not NAB Mice

We next examined whether NAcb-DBS would be able to alter the enhanced depression-like behavior of SSRIinsensitive $\mathrm{HAB}$ mice. A single session of NAcb-DBS had no effect and resulted in unaltered time spent immobile compared with NAcb-sham HAB animals both in the FST $(t=0.576, P=0.577$; Figure $3 \mathrm{a})$ and TST $(t=-0.580$, $P=0.573$; Figure $3 \mathrm{~b}$ ). In contrast, $\mathrm{HAB}$ mice receiving repeated $(7 \times)$ NAcb-DBS displayed a reduced amount of time spent immobile both in the FST $(t=3.021$, $P=0.007$; Figure $3 \mathrm{a})$ and the TST $(t=3.001, P=0.008$; Figure $3 \mathrm{~b}$ ), indicating a robust antidepressant effect. Next, we investigated whether NAcb-DBS could affect the depression-like behavior of NAB mice, which similar to non-depressed human subjects (Barr et al, 1997; Gelfin et al, 1998) do not respond to pharmacological interventions (Sah et al, 2012). Indeed, neither single $(t=0.949, P=0.356)$ nor repeated $(t=0.302, P=0.767)$ NAcb-DBS altered the depression-like behavior of NAB mice (Supplementary Figure S2A), suggesting that repeated NAcb-DBS is only effective in deranged, that is, pathophysiological, systems using the present stimulation conditions.

\section{NAcb-DBS Reduced Anxiety-Related Behavior in HAB, but not NAB Mice}

Given that $\mathrm{HAB}$ mice are characterized by enhanced anxiety-related behavior (Kromer et al, 2005), we also studied possible effects of NAcb-DBS on emotionality in HABs. In comparison with NAcb-sham HAB controls, four repetitions of NAcb-DBS greatly reduced the latency to eat a preferred food offered in the center of the testing area of the novelty suppressed feeding paradigm $(t=3.064, P=0.007$; Figure $3 c$ ), indicating a clear anxiolytic effect in HAB mice. In contrast, there was no significant anxiolytic effect of repeated NAcb-DBS as compared with NAcb-sham in NAB animals ( $t=1.684, P=0.111$; Supplementary Figure S2B).

\section{NAcb-DBS did not Influence Locomotor Activity of HAB Mice}

To exclude the possibility that the observed behavioral changes following repeated NAcb-DBS were affected by 
unspecific alterations in general locomotion, locomotor activity of animals was studied in an open field (see scheme in Figure 2a). Following five DBS stimulations, the distance traveled in the open field by HAB mice did not differ within the first $5 \mathrm{~min}(t=1.410, P=0.178)$, reflecting the testing period of the TST and FST, or during the total $10 \mathrm{~min}$ testing time $(t=0.007, P=0.994$; Table 1$)$.

\section{NAcb-DBS Enhanced Adult Hippocampal Neurogenesis in $\mathrm{HAB}$ Mice}

To examine possible underlying mechanisms of successful NAcb-DBS, we next studied whether repeated NAcb-DBS would increase adult hippocampal neurogenesis in $\mathrm{HAB}$ mice, as this has been previously shown for various other
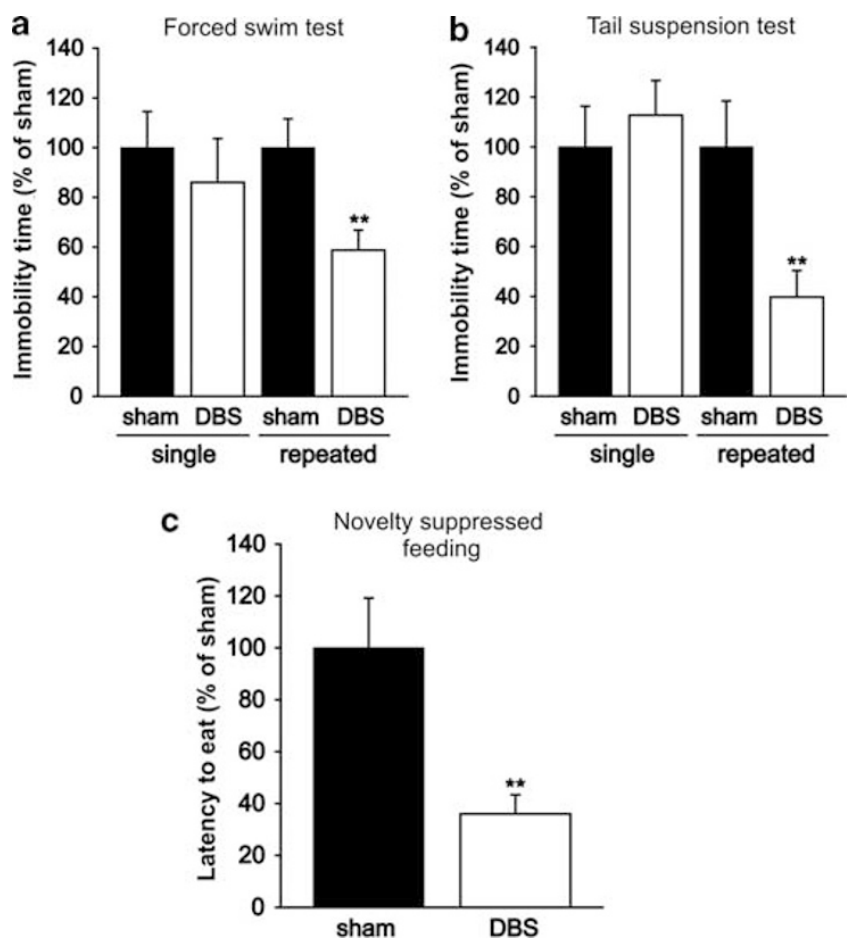

Figure 3 Effect of single and repeated deep brain stimulation of the nucleus accumbens (NAcb-DBS) on depression- and anxiety-related behaviors in high anxiety-related behavior (HAB) mice. Repeated $(7 \times)$, but not single, NAcb-DBS robustly decreased the period of immobility during the forced swim test (a) and the tail suspension test (b), demonstrating antidepressant effects. Four repetitions of NAcb-DBS reduced the latency to eat the preferred food offered in the center of the testing area during the novelty suppressed feeding paradigm (c), indicating an anxiolytic effect. Data represent means \pm SEM. $N=7-||$ animals per group; ${ }^{*} * P<0.0$ I, for NAcb-DBS vs NAcb-sham HAB mice.

Table I Effects of NAcb-DBS in HAB Mice on Locomotor Activity Displayed in the Open Field Test

\begin{tabular}{lcc}
\hline Time frame (min) & NAcb-Sham (cm) & NAcb-DBS (cm) \\
\hline $0-5$ & $1101 \pm 123$ & $1200 \pm 151$ \\
$6-10$ & $1268 \pm 59$ & $1047 \pm 115$ \\
$0-10$ & $2368 \pm 148$ & $2248 \pm 242$ \\
\hline
\end{tabular}

Data represent the distance traveled (in $\mathrm{cm}$ ) in the open field and are given as means \pm SEM. $N=8-10$ animals per group. antidepressant interventions, including pharmacotherapy and electroconvulsive seizures (for a review see Samuels and Hen, 2011). Indeed, in HAB mice, DCX immunohistochemistry revealed an enhanced number of immature neurons in the dentate gyrus of the HPC following repeated NAcb-DBS as compared with NAcb-sham conditions $(t=2.706, \quad P=0.015$; Figures $4 \mathrm{a}$ and $\mathrm{c}$ or $t=2.914$, $P=0.001$; Figures $4 \mathrm{e}$ and $\mathrm{g}$ ). In addition, BrdU was injected either before NAcb-DBS or during NAcb-DBS (see Figure 2a, Experiments 3 and 4) to reveal putatively different effects of NAcb-DBS at different developmental stages of newly born cells. It was observed that the number of BrdU-positive cells was increased following NAcb-DBS treatment as compared with NAcb-Sham condition when BrdU was injected before NAcb-DBS $(t=2.361, P=0.030$;

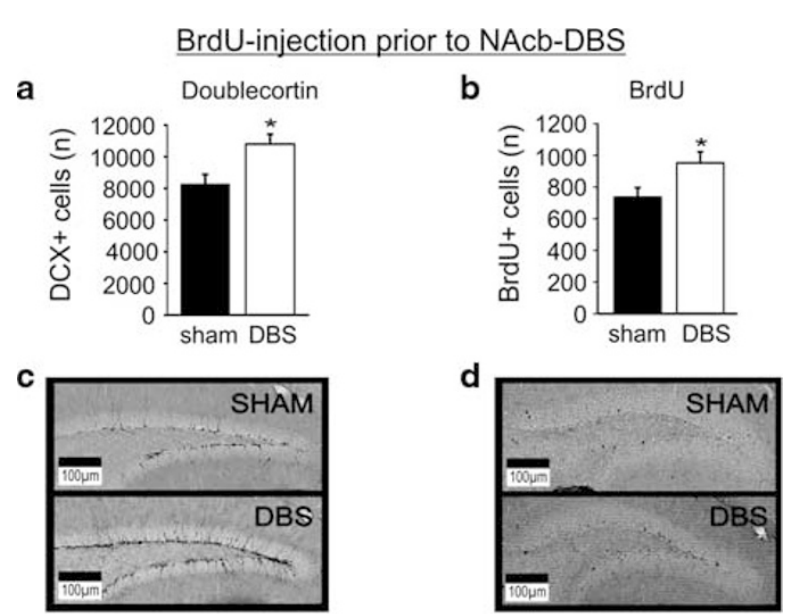

BrdU-injection during NAcb-DBS e

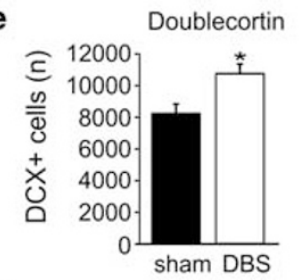

g

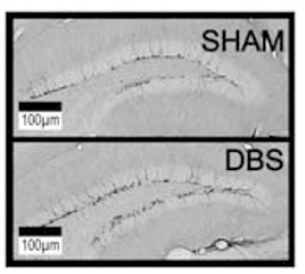

f

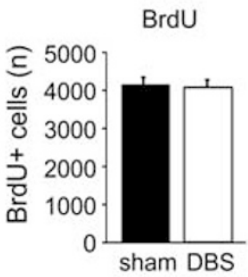

h

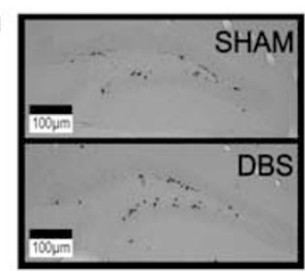

Figure 4 Effect of repeated deep brain stimulation of the nucleus accumbens (NAcb-DBS) on adult hippocampal neurogenesis in high anxiety-related behavior (HAB) mice. 7 days of NAcb-DBS enhanced the number of doublecortin-positive $(\mathrm{DCX}+)$ cells in the dentate gyrus of the entire hippocampus ( $\mathrm{a}, \mathrm{c}$ and e, g). 5-Bromo-2'-deoxyuridine (BrdU) injection before NAcb-DBS resulted in an enhanced number of BrdUlabeled cells in the dentate gyrus of the hippocampus (b, d), whereas the number of BrdU-positive cells born during NAcb-DBS did not differ between treatment groups ( $f, h)$. Representative photographs (scale bar $=100 \mu \mathrm{m}$ ) showing DCX- and BrdU-positive cells in the dentate gyrus of the hippocampus of NAcb-DBS and NAcb-sham HAB mice when BrdU was injected either before NAcb-DBS (c, d) or during NAcb-DBS $(g, h)$. Data represent means \pm SEM. $N=9$ - 10 animals per group; $* P<0.05$ for NAcb-DBS vs NAcb-sham HAB mice. 
Figures $4 \mathrm{~b}$ and $\mathrm{d})$, but not during NAcb-DBS $(t=0.268$, $P=0.792$; Figures $4 \mathrm{f}$ and $\mathrm{h}$ ).

\section{NAcb-DBS Modulated Challenge-Induced Neuronal Activation Patterns in HAB Mice}

An overview of c-Fos expression in the analyzed brain areas and $P$-values are given in Table 2. Repeated NAcb-DBS modulated stress-induced neuronal activity in four out of seven investigated areas. In comparison with their NAcb-sham controls, in NAcb-DBS-treated HAB mice the numbers of c-Fos-positive cells were significantly enhanced in the lateral OFC, lateral habenula, and dentate gyrus of the HPC, while c-Fos induction was reduced in the prelimbic cortex only (Figure 5).

\section{DISCUSSION}

The applicability of DBS is currently being evaluated in various psychiatric indications including TRD (Fisher et al, 2010; for a review see Luigjes et al, 2012). Yet, the investigation of its underlying mechanisms is limited in humans for understandable reasons, and preclinical data showing the behavioral efficacy of DBS as well as its neurobiological correlates are rare in psychopathologically relevant animal models. Motivated by these facts, we initially further validated the unique $\mathrm{HAB}$ mouse model of

Table 2 Modulation of Swim Stress-Induced c-Fos Expression by NAcb-DBS in HAB mice

\begin{tabular}{|c|c|c|c|}
\hline Brain regions (brain level) & HAB-Sham & HAB-DBS & $P$-value \\
\hline \multicolumn{4}{|l|}{ Cortical areas } \\
\hline $\begin{array}{l}\text { Prelimbic cortex }(+1.94 \mathrm{~mm} \\
\text { and }+1.70 \mathrm{~mm})\end{array}$ & $15.8 \pm 0.5$ & $13.3 \pm 0.5$ & 0.008 \\
\hline $\begin{array}{l}\text { Infralimbic cortex }(+1.94 \mathrm{~mm} \\
\text { and }+1.70 \mathrm{~mm})\end{array}$ & $11.7 \pm 0.4$ & $13.0 \pm 0.6$ & 0.163 \\
\hline $\begin{array}{l}\text { Cingulate cortex I }(+1.94 \mathrm{~mm} \\
\text { and }+1.70 \mathrm{~mm})\end{array}$ & $31.6 \pm 2.4$ & $34.2 \pm 2.7$ & 0.706 \\
\hline $\begin{array}{l}\text { Orbitofrontal cortex, lateral } \\
(+1.94 \mathrm{~mm})\end{array}$ & $33.4 \pm 3.7$ & $43.3 \pm 2.0$ & 0.027 \\
\hline \multicolumn{4}{|l|}{ Thalamus } \\
\hline $\begin{array}{l}\text { Lateral habenular nucleus } \\
(-1.06 \mathrm{~mm})\end{array}$ & $50.9 \pm 1.8$ & $57.8 \pm 0.9$ & 0.003 \\
\hline $\begin{array}{l}\text { Medial habenular nucleus } \\
(-1.06 \mathrm{~mm})\end{array}$ & $28.9 \pm 1.1$ & $28.0 \pm 2.6$ & 0.770 \\
\hline \multicolumn{4}{|l|}{ Hippocampus } \\
\hline $\begin{array}{l}\text { Dentate gyrus ( }-0.94 \text { to } \\
-3.80 \mathrm{~mm})\end{array}$ & $3040 \pm 137.2$ & $3664 \pm 234.7$ & 0.040 \\
\hline $\begin{array}{l}\text { Dentate gyrus, superior arm } \\
(-0.94 \text { to }-3.80 \mathrm{~mm})\end{array}$ & $2356 \pm 98.6$ & $2924.3 \pm 94.0$ & $<0.001$ \\
\hline $\begin{array}{l}\text { Dentate gyrus, inferior arm } \\
(-0.94 \text { to }-3.80 \mathrm{~mm})\end{array}$ & $738.7 \pm 57.7$ & $911.0 \pm 66.4$ & 0.068 \\
\hline
\end{tabular}

Data represent means \pm SEM numbers of c-Fos-positive cells per $0.01 \mathrm{~mm}^{2}$ (except dentate gyrus of the hippocampus where total c-Fos expression was quantified). $N=9-1$ I animals per group.

Bold and italic numerals indicate significant differences in the number of c-Fospositive cells between Nacb-DBS and NAcb-sham HAB mice. $P<0.05$. comorbid trait anxiety- and depression-like behavior (Kromer et al, 2005; Landgraf et al, 2007; Sah et al, 2012) by demonstrating that these mice are resistant to the antidepressant effects of chronic SSRI treatment, the firstline therapy for depression as well as many anxiety disorders (Koenig and Thase, 2009). In contrast, repeated NAcb-DBS rescued the enhanced depression- and anxietyrelated behavior of $\mathrm{HAB}$ animals. This effect coincided with (i) distinct changes in stress-induced neuronal activation of depression-related brain areas, including cortical areas and the HPC, as well as (ii) increased adult hippocampal neurogenesis.

\section{HAB Mice Displayed Features of TRD}

HAB mice display enhanced depression-like behavior as well as altered stress-induced neuronal activity in
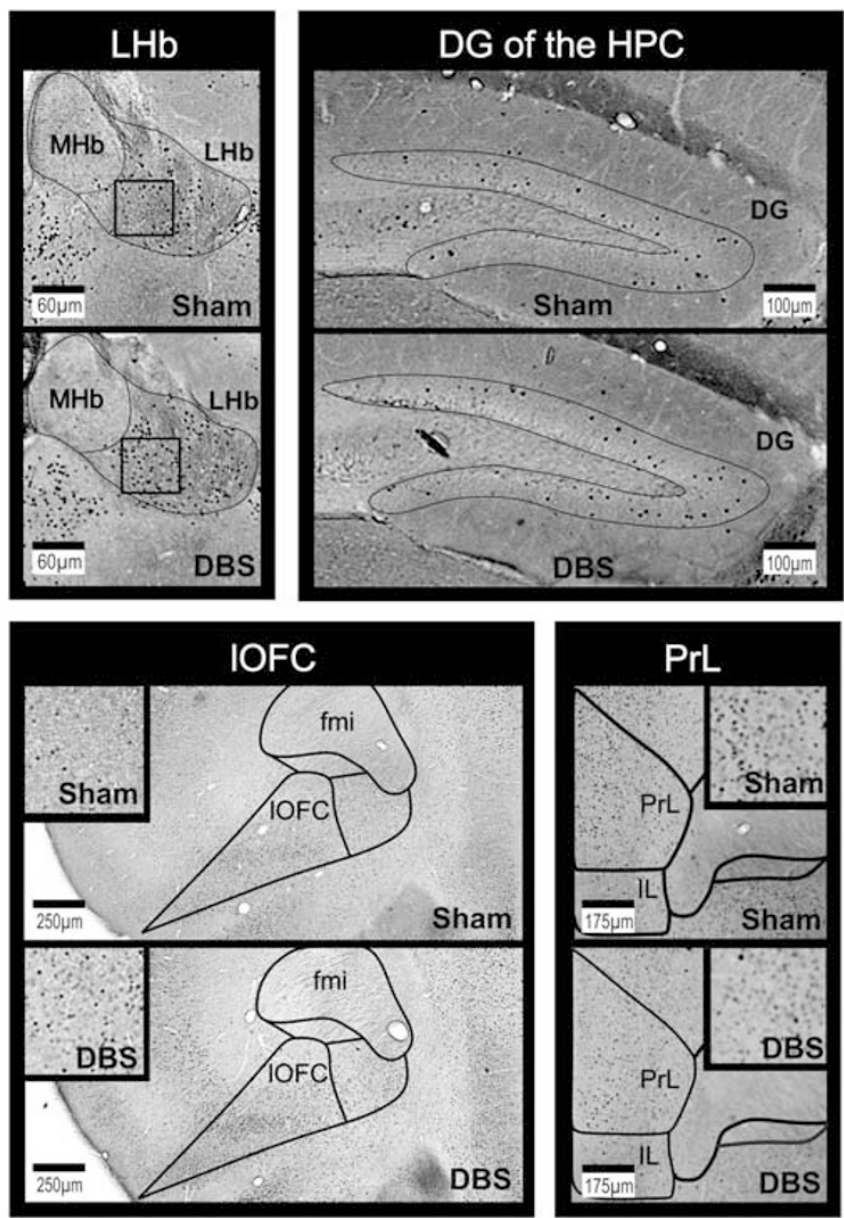

Figure 5 Effect of repeated deep brain stimulation of the nucleus accumbens (NAcb-DBS) on c-Fos induction in high anxiety-related behavior (HAB) mice following swim stress. With the help of a mouse brain atlas (Franklin and Paxinos, 2007), those selected brain regions in which c-Fos expression was quantified were delineated in representative photographs comparing NAcb-DBS and NAcb-sham HAB mice. High magnification photographs of c-Fos expression are inserted for selected brain regions (scale bars as indicated). LHb, lateral habenula; $\mathrm{MHb}$, medial habenula; DG, dentate gyrus; HPC, hippocampus; IOFC, lateral orbitofrontal cortex; fmi, forceps minor of the corpus callosum; PrL, prelimbic cortex; IL, infralimbic cortex. 
networks related to depression and anxiety in comparison with their normal depression/anxiety NAB counterparts (Sah et al, 2012; Sartori et al, 2011b). In this study, we demonstrate for the first time that male HABs are insensitive to at least three SSRIs differing in half-life, plasmabinding, active metabolites, and $K_{\mathrm{i}}$ values of 5-HT uptake (Hiemke and Hartter, 2000). Interestingly, we observed that treatment resistance seemed to be restricted to drugs targeting solely the serotonergic system, as both the selective noradrenaline re-uptake inhibitor reboxetine and the tricyclic antidepressant desipramine significantly reduced the depression-like behavior of $\mathrm{HAB}$ mice. This finding was surprising further suggesting that male $\mathrm{HAB}$ mice represent a valid model to study treatment resistance against SSRIs in humans. Indeed, at least $33 \%$ of patients do not respond to first-line pharmacotherapies such as the SSRI citalopram (Koenig and Thase, 2009; Trivedi et al, 2006). Changed responsiveness to SSRI treatment in humans has been linked to SNPs affecting 5-HT synthesis and polymorphism in the 5-HTT promoter region as well as functional polymorphisms in the $5-\mathrm{HT}_{1 \mathrm{~A}}$ and $5-\mathrm{HT}_{1 \mathrm{~B}}$ receptor genes (for a review see Kroeze et al, 2012). However, while an aberrant 5-HT neurotransmission has been reported in male $\mathrm{HAB}$ rats (Keck et al, 2005), pathophysiological correlates underlying the selective insensitivity to SSRIs in HAB mice remain to be elucidated in further experiments.

To date, there are only a few reports on TRD in animal models of depression. For example, the Flinders sensitive rat line has recently been described as being insensitive to citalopram and nortryptilin when subjected to repeated maternal separation (Borsini, 2012; Carboni et al, 2010). Furthermore, congenital learned-helplessness rats and about a quarter of rats subjected to unpredictable mild stress do not respond to chronic treatment with desipramine or fluoxetine, or to electroconvulsive therapy, respectively (Sartorius et al, 2007; Wang et al, 2011). It is possible that in the past insensitivities to certain drug classes were less likely to be reported. However, more recently the restriction of predictive validity of animal models for depression has been (partially) eased as a consequence of the need to model TRD (Borsini, 2012; Samuels and Hen, 2011) and to test new antidepressant approaches not primarily acting via monoaminergic systems.

\section{NAcb-DBS Elicited Antidepressant and Anxiolytic Effects in HAB Mice}

In this study, we show for the first time that NAcb-DBS reduced depression-like behavior in an SSRI-insensitive animal model for enhanced depression-like behavior. While acute stimulation was not sufficient, repeated high-frequency stimulation caused a robust antidepressant effect in HAB mice. Similarly, in patients with TRD, significant reductions in depressive symptomatology reaching response or remission end points also seem to require more time (Bewernick et al, 2010; Lozano et al, 2008), despite some rapid effects on specific symptoms seen during or following early phases of DBS (Schlaepfer et al, 2008; Mayberg et al, 2005). These findings, thus, suggest that at least some of the behavioral changes induced by NAcb-DBS may require long-term changes such as modulation of neuroplasticity. Indeed, in rats, pERK expression (an early marker of cell plasticity) is enhanced in prefrontal and orbitofrontal regions as well as in the amygdala following DBS of the NAcb/ventral striatum (Rodriguez-Romaguera et al, 2012). In addition to its antidepressant effects, repeated NAcb-DBS reduced the enhanced trait anxiety of $\mathrm{HAB}$ mice to an extent comparable to that achieved after anxiolytic treatment (Gaburro et al, 2011; Kromer et al, 2005; Sartori et al, 2011a; for a review see Sartori et al, 2011b). Underlining the translational value of the present findings in $\mathrm{HAB}$ mice, similar effects were also observed in humans (Bewernick et al, 2012; Denys et al, 2010).

Various behaviors, including locomotion, seem to be rapidly altered by interference with the NAcb function. As both ablation (Parkinson et al, 1999) and electrical stimulation (van Kuyck et al, 2007) of the NAcb affect activity and exploratory behavior in animals and/or humans, we tested whether NAcb-DBS under our stimulation condition produces changes in general locomotor activity, which could potentially influence behavioral assessment of anxiolytic and antidepressant effects. This possibility could be excluded, as it was found that NAcb-sham and NAcbDBS mice did not differ in terms of distance traveled in the open field, indicating no effect on locomotion using the present high-frequency stimulation settings.

To clarify whether the behavioral effects of NAcb-DBS were restricted to acting only on pathophysiologically deranged as opposed to physiological networks, we investigated the behavioral outcome of repeated NAcbDBS in NABs. Neither single nor repeated NAcb-DBS affected the level of depression- and anxiety-like behavior in NAB mice, indicating that NAcb-DBS (at the chosen stimulation settings) preferentially acts on systems of altered/enhanced emotionality. In support of this idea, van der Plasse et al (2012) recently reported inefficacy of NAcb-DBS in terms of its ability to affect depression-like behavior displayed by normal rats. Mood-elevating effects of antidepressants are predominantly observed in depressed patients (Barr et al, 1997; Gelfin et al, 1998; Yeragani et al, 2003), suggesting that the neurobiological targets of antidepressants in pathophysiologically deranged systems differ from those in intact systems (Berton and Nestler, 2006). Therefore, while some aspects of therapeutic efficacy of DBS may be shared by normal animals (Hamani et al, 2010; Rodriguez-Romaguera et al, 2012) and pathophysiological models (Falowski et al, 2011; Friedman et al, 2012; Hamani et al, 2012), some critical changes underlying their antidepressant effect will remain undetected if animals reflecting physiological but not pathophysiological conditions are used.

\section{Neurobiological Changes Induced by NAcb-DBS in HAB Mice}

Alteration of challenge-induced neuronal activation patterns. The NAcb receives projections from the main monoaminergic nuclei including the raphe nuclei and the locus coeruleus and from regions associated with locomotion, emotion, and memory, including the globus pallidus, the amygdala, the cortex, and the HPC (Nauto and Domesick, 1984). In turn, NAcb projects to pallidal and nigral complexes, to cortical areas such as the medial prefrontal cortex, and to the thalamic and hypothalamic regions. Several of these brain areas have been implicated in 
the pathophysiology of depression and/or in the processing of antidepressant effects (Krishnan and Nestler, 2008). Furthermore, many of these areas are positioned along the superolateral arm of the medial forebrain bundle, a structure related to the reward circuitry, likely to be stimulated by most of, if not all, the different electrode placements (eg the anterior limb of the internal capsule, the subgenual cingulate gyrus, the NAcb) used in the treatment of TRD patients (Coenen et al, 2011). Regarding potential mechanisms of action identified so far, DBS preferentially modulates network fibers passing the electrode, while local effects of DBS on somatodendritc structures are minor (McIntyre and Grill, 1999; McIntyre et al, 2004; Nowak and Bullier, 1998a, b). Specifically, direct inhibition of the electrode target area by muscimol injections or radiofrequency lesions does not seem to resemble effects of DBS on anxiety/depression networks (Hamani et al, 2010; Rodriguez-Romaguera et al, 2012). To identify distant parts of circuitries affected by NAcb-DBS at the present stimulation conditions, which may underlie the antidepressant effect observed in HAB mice, we used c-Fos mapping in specific brain areas (Singewald, 2007). The focus was laid upon those brain areas that have been previously shown to be associated with therapeutic modulation of enhanced depression-like behavior (Muigg et al, 2007; Sah et al, 2012; Winter et al, 2011).

One candidate area is the HPC, a highly stress-sensitive key brain structure dysregulated in depression (Floresco et al, 2001; Kingwell, 2010) in terms of reduced volume and dysfunctional activation under emotional challenge (Kempton et al, 2011; Lee et al, 2007; Milne et al, 2012; Tan et al, 2012; also see Disner et al (2011)). Interestingly, HAB rats (Muigg et al, 2007; Salomé et al, 2004), and more recently $\mathrm{HAB}$ mice (Muigg et al, 2009; Sah et al, 2012), display hypoactivation of the dentate gyrus (DG) by stress challenge. Here, we observed that NAcb-DBS enhanced the c-Fos induction in response to FST stress, suggesting that (i) neuronal DG activity is restored in HAB mice, and (ii) DG activity is strongly correlated with depression-like behavior. To our knowledge, so far changes in DG/HPC activity have not been reported in TRD patients undergoing DBS, while activity of the HPC is enhanced in addicted patients undergoing NAcb-DBS (Heldmann et al, 2012).

In addition, the c-Fos response was enhanced in the OFC and the lateral habenula, but attenuated in the prelimbic cortex following FST. In line with our results, pERK expression is enhanced in prefrontal regions, including the OFC, following ventral striatum/NAcb-DBS, suggesting functional connectivity between these spatially distinct structures (Rodriguez-Romaguera et al, 2012). In further support of our findings, McCracken and Grace $(2007,2009)$ propose an antidromic activation of NAcbinput fibers descending from the OFC by NAcb-DBS, resulting in the modulation of activity within the OFC and, thus, potentially affecting disturbed communication between prefrontal areas, limbic areas, and the OFC in an ultimately beneficial way.

$N A c b-D B S$ enhanced the number of immature neurons in the DG of the HPC. Whereas stress as a triggering factor for depression attenuates adult neurogenesis in the HPC, antidepressant treatment enhances proliferation and survival in the hippocampal neurogenic niche and has been proposed to be at least partially required for antidepressant efficacy (for a review see Samuels and Hen, 2011). Given that HAB mice display reduced adult hippocampal neurogenesis in comparison with NABs (Sah et al, 2012), we also investigated whether the blunted neurogenesis of HABs would be affected by NAcb-DBS. Indeed, the number of DCX-positive cells was enhanced in the DG in NAcb-DBStreated HAB mice in comparison with NAcb-sham controls. This finding points towards enhanced adult hippocampal neurogenesis, as DCX is exclusively expressed in neuronal precursors and not fully differentiated neurons reflecting the developmental stages of neuroblast 1 and 2 cells as well as immature neurons (for a review see Encinas et al, 2006). Similarly, DBS of the anterior thalamic nucleus slightly increases the number of neuroblast 1 cells in the HPC, while the symmetric division of amplifying neuronal progenitors is its main effect (Encinas et al, 2006, 2011; Toda et al, 2008). To gain insight into the effect of NAcb-DBS on different developmental stages of newly born cells, BrdU staining was used. Interestingly, only when BrdU was injected before, but not during NAcb-DBS, an enhanced number of BrdU-positive cells was found. These results suggest that the higher number of DCX-positive neurons reflects a cell cohort, which was actually born before the NAcb-DBS intervention and whose survival was then increased by NAcb-DBS. This is supported by a recent study showing that a single DBS session of the entorhinal cortex increases the survival rate of cells born up to 10 days before DBS in the DG (Stone et al, 2011). In this context, it is speculated that 1- to 3-week-old progenitors are especially sensitive to life events that promote survival (eg environmental enrichment) or deteriorate it (eg through stressful condition; Zhao et al, 2008). However, future work will need to verify whether these cells contribute to the reduction of depressive symptoms.

In summary, the data presented here demonstrate that NAcb-DBS selectively rescued the enhanced depression- and anxiety-related behaviors in an SSRI-resistant psychopathological mouse model of high trait depression/ anxiety without affecting these behaviors in normal depression/anxiety $\mathrm{NAB}$ controls. The specific changes that occurred in challenge-induced neuronal activation suggest that the beneficial effects of NAcb-DBS are mediated via a distributed network that includes the HPC, and cortical and thalamic areas. Furthermore, enhanced adult neurogenesis following repeated NAcb-DBS indicates that long-term alterations may also be an important part of the mechanism(s) of NAcb-DBS, leading to a rescue of exaggerated anxiety- and depression-like symptoms.

\section{ACKNOWLEDGEMENTS}

This work was supported by research grants from the Austrian Science Fund (FWF, W 1206-B18 SPIN) and Hope for Depression Research/ ISAN (to NS).

\section{DISCLOSURE}

The authors declare no conflict of interest. 


\section{REFERENCES}

Al-Harbi KS (2012). Treatment-resistant depression: therapeutic trends, challenges, and future directions. Patient Pref Adher 6: 369-388.

Barr LC, Heninger GR, Goodman W, Charney DS, Price LH (1997). Effects of fluoxetine administration on mood response to tryptophan depletion in healthy subjects. Biol Psychiatry 41: 949-954.

Benabid AL, Benazzous A, Pollak P (2002). Mechanisms of deep brain stimulation. Mov Disor 17(Suppl 3): S73-S74.

Berton O, Nestler EJ (2006). New approaches to antidepressant drug discovery: beyond monoamines. Nat Rev Neurosci 7: 137-151.

Bewernick BH, Hurlemann R, Matusch A, Kayser S, Grubert C, Hadrysiewicz B et al (2010). Nucleus accumbens deep brain stimulation decreases ratings of depression and anxiety in treatment-resistant depression. Biol Psychiatry 67: 110-116.

Bewernick BH, Kayser S, Sturm V, Schlaepfer TE (2012). Longterm effects of nucleus accumbens deep brain stimulation in treatment-resistant depression: evidence for sustained efficacy. Neuropsychopharmacology 37: 1975-1985.

Borsini F (2012). Models for depression in drug screening and preclinical studies: future directions. World J Pharmacol 1: 21-29.

Carboni L, Becchi S, Piubelli C, Mallei A, Giambelli R, Razzoli M et al (2010). Early-life stress and antidepressants modulate peripheral biomarkers in a gene-environment rat model of depression. Prog Neuro-Psycharm Biol Psych 34: 1037-1048.

Coenen VA, Schlaepfer TE, Maedler B, Panksepp J (2011). Crossspecies affective functions of the medial forebrain bundleimplications for the treatment of affective pain and depression in humans. Neurosci Biobehav Rev 35: 1971-1981.

Couillard-Despres S, Wuertinger C, Kandasamy M, Caioni M, Stadler K, Aigner R et al (2009). Ageing abolishes the effects of fluoxetine on neurogenesis. Mol Psychiatry 14: 856-864.

Cryan JF, Mombereau C (2004). In search of a depressed mouse: utility of models for studying depression-related behavior in genetically modified mice. Mol Psychiatry 9: 326-357.

Cryan JF, Mombereau C, Vassout A (2005). The tail suspension test as a model for assessing antidepressant activity: review of pharmacological and genetic studies in mice. Neurosci Biobehav Rev 29: 571-625.

Denys D, Mantione M, Figee M, van den Munckhof P, Koerselman F, Westenberg H et al (2010). Deep brain stimulation of the nucleus accumbens for treatment-refractory obsessive-compulsive disorder. Arch Gen Psychiatry 67: 1061-1068.

Disner SG, Beevers CG, Haigh EA, Beck AT (2011). Neural mechanisms of the cognitive model of depression. Nat Rev Neurosci 12: 467-477.

Dostrovsky JO, Lozano AM (2002). Mechanisms of deep brain stimulation. Movem Disord 17(Suppl 3): S63-S68.

Encinas JM, Hamani C, Lozano AM, Enikolopov G (2011). Neurogenic hippocampal targets of deep brain stimulation. J Comp Neurol 519: 6-20.

Encinas JM, Vaahtokari A, Enikolopov G (2006). Fluoxetine targets early progenitor cells in the adult brain. Proc Natl Acad Sci USA 103: $8233-8238$.

Falowski SM, Sharan A, Reyes BA, Sikkema C, Szot P, Van Bockstaele EJ (2011). An evaluation of neuroplasticity and behavior after deep brain stimulation of the nucleus accumbens in an animal model of depression. Neurosurgery 69: 1281-1290.

Fisher R, Salanova V, Witt T, Worth R, Henry T, Gross R et al (2010). Electrical stimulation of the anterior nucleus of thalamus for treatment of refractory epilepsy. Epilepsia 51: 899-908.

Floresco SB, Todd CL, Grace AA (2001). Glutamatergic afferents from the hippocampus to the nucleus accumbens regulate activity of ventral tegmental area dopamine neurons. J Neurosci 21: 4915-4922.
Fostick L, Silberman A, Beckman M, Spivak B, Amital D (2010). The economic impact of depression: resistance or severity? Eur Neuropsychopharmacol 20: 671-675.

Franklin KBJ, Paxinos G (2007). The Mouse Brain in Stereotaxic Coordinates. 3rd edn Elsevier Academic Press: New York, USA.

Friedman A, Lax E, Abraham L, Tischler H, Yadid G (2012). Abnormality of VTA local field potential in an animal model of depression was restored by patterned DBS treatment. Eur Neuropsychopharmacol 22: 64-71.

Gaburro S, Stiedl O, Giusti P, Sartori SB, Landgraf R, Singewald N (2011). A mouse model of high trait anxiety shows reduced heart rate variability that can be reversed by anxiolytic drug treatment. Int J Neuropsychopharmacol 14: 1341-1355.

Gelfin Y, Gorfine M, Lerer B (1998). Effect of clinical doses of fluoxetine on psychological variables in healthy volunteers. $A m \mathrm{~J}$ Psychiatry 155: 290-292.

Gorwood P (2008). Neurobiological mechanisms of anhedonia. Dialog Clin Neurosci 10: 291-299.

Gutman DA, Holtzheimer PE, Behrens TE, Johansen-Berg H, Mayberg HS (2009). A tractography analysis of two deep brain stimulation white matter targets for depression. Biol Psychiatry 65: 276-282.

Haber SN, Knutson B (2010). The reward circuit: linking primate anatomy and human imaging. Neuropsychopharmacol 35: 4-26.

Hamani C, Diwan M, Macedo CE, Brandao ML, Shumake J, Gonzalez-Lima F et al (2010). Antidepressant-like effects of medial prefrontal cortex deep brain stimulation in rats. Biol Psychiatry 67: 117-124.

Hamani C, Machado DC, Hipolide DC, Dubiela FP, Suchecki D, Macedo CE et al (2012). Deep brain stimulation reverses anhedonic-like behavior in a chronic model of depression: role of serotonin and brain derived neurotrophic factor. Biol Psychiatry 71: 30-35.

Heldmann M, Berding G, Voges J, Bogerts B, Galazky I, Muller U et al (2012). Deep brain stimulation of nucleus accumbens region in alcoholism affects reward processing. PLoS One 7: e36572.

Hiemke C, Hartter S (2000). Pharmacokinetics of selective serotonin reuptake inhibitors. Pharmacol Ther 85: 11-28.

Hoyer C, Kranaster L, Sartorius A, Hellweg R, Gass P (2012). Longterm course of brain-derived neurotrophic factor serum levels in a patient treated with deep brain stimulation of the lateral habenula. Neuropsychobiology 65: 147-152.

Keck ME, Sartori SB, Welt T, Muller MB, Ohl F, Holsboer F et al (2005). Differences in serotonergic neurotransmission between rats displaying high or low anxiety/depression-like behaviour: effects of chronic paroxetine treatment. J Neurochem 92: 1170-1179.

Kelley AE, Stinus L (1984). The distribution of the projection from the parataenial nucleus of the thalamus to the nucleus accumbens in the rat: an autoradiographic study. Exp Brain Res 54: 499-512.

Kempton MJ, Salvador Z, Munafo MR, Geddes JR, Simmons A, Frangou $S$ et al (2011). Structural neuroimaging studies in major depressive disorder. Meta-analysis and comparison with bipolar disorder. Arch Gen Psychiatry 68: 675-690.

Kessler RC, Berglund P, Demler O, Jin R, Merikangas KR, Walters EE (2005). Lifetime prevalence and age-of-onset distributions of DSM-IV disorders in the National Comorbidity Survey Replication. Arch Gen Psychiatry 62: 593-602.

Kingwell K (2010). Depression: In pursuit of happiness. Nat Rev Neurosci 11: 786.

Koenig AM, Thase ME (2009). First-line pharmacotherapies for depression-what is the best choice? Pol Arch Med Wewn 119: $478-486$.

Kringelbach ML, Green AL, Owen SL, Schweder PM, Aziz TZ (2010). Sing the mind electric-principles of deep brain stimulation. Eur J Neurosci 32: 1070-1079. 
Krishnan V, Nestler EJ (2008). The molecular neurobiology of depression. Nature 455: 894-902.

Kroeze Y, Zhou H, Homberg JR (2012). The genetics of selective serotonin reuptake inhibitors. Pharmacol Ther 136: 375-400.

Kromer SA, Kessler MS, Milfay D, Birg IN, Bunck M, Czibere L et al (2005). Identification of glyoxalase-I as a protein marker in a mouse model of extremes in trait anxiety. $J$ Neurosci 25: 4375-4384.

Landgraf R, Kessler MS, Bunck M, Murgatroyd C, Spengler D, Zimbelmann $\mathrm{M}$ et al (2007). Candidate genes of anxiety-related behavior in $\mathrm{HAB} / \mathrm{LAB}$ rats and mice: focus on vasopressin and glyoxalase-I. Neurosci Biobehav Rev 31: 89-102.

Lee BT, Seong Whi C, Hyung Soo K, Lee BC, Choi IG, Lyoo IK et al (2007). The neural substrates of affective processing toward positive and negative affective pictures in patients with major depressive disorder. Prog Neuro-Psycharm Biol Psych 31: 1487-1492.

Lim LW, Tan SK, Groenewegen HJ, Temel Y (2011). Electrical brain stimulation in depression: which target(s)? Biol Psychiatry 69: e5-e6 author reply e7-8.

Lozano AM, Giacobbe P, Hamani C, Rizvi SJ, Kennedy SH, Kolivakis TT et al (2012). A multicenter pilot study of subcallosal cingulate area deep brain stimulation for treatment-resistant depression. J Neurosurg 116: 315-322.

Lozano AM, Mayberg HS, Giacobbe P, Hamani C, Craddock RC, Kennedy SH (2008). Subcallosal cingulate gyrus deep brain stimulation for treatment-resistant depression. Biol Psychiatry 64: 461-467.

Luciano M, Del Vecchio V, Giacco D, De Rosa C, Malangone C, Fiorillo A (2012). A 'family affair'? The impact of family psychoeducational interventions on depression. Expert Rev Neurother 12: 83-91.

Luigjes J, de Kwaasteniet BP, de Koning PP, Oudijn MS, van den Munckhof P, Schuurman PR et al (2012). Surgery for psychiatric disorders. World Neurosurg, doi:10.1016/j.wneu.2012.03.009 (in press).

Malone DA Jr, Dougherty DD, Rezai AR, Carpenter LL, Friehs GM, Eskandar EN et al (2009). Deep brain stimulation of the ventral capsule/ventral striatum for treatment-resistant depression. Biol Psychiatry 65: 267-275.

Mayberg HS, Lozano AM, Voon V, McNeely HE, Seminowicz D, Hamani C et al (2005). Deep brain stimulation for treatmentresistant depression. Neuron 45: 651-660.

McCracken CB, Grace AA (2007). High-frequency deep brain stimulation of the nucleus accumbens region suppresses neuronal activity and selectively modulates afferent drive in rat orbitofrontal cortex in vivo. J Neurosci 27: 12601-12610.

McCracken CB, Grace AA (2009). Nucleus accumbens deep brain stimulation produces region-specific alterations in local field potential oscillations and evoked responses in vivo. J Neurosci 29: 5354-5363.

McIntyre CC, Grill WM (1999). Excitation of central nervous system neurons by nonuniform electric fields. Biophys J 76: 878-888.

McIntyre CC, Savasta M, Walter BL, Vitek JL (2004). How does deep brain stimulation work? Present understanding and future questions. J Clin Neurophysiol 21: 40-50.

Milne AM, MacQueen GM, Hall GB (2012). Abnormal hippocampal activation in patients with extensive history of major depression: an fMRI study. J Psychiatry Neurosci 37: 28-36.

Moreines JL, McClintock SM, Holtzheimer PE (2011). Neuropsychologic effects of neuromodulation techniques for treatmentresistant depression: a review. Brain Stimul 4: 17-27.

Muigg P, Hoelzl U, Palfrader K, Neumann I, Wigger A, Landgraf R et al (2007). Altered brain activation pattern associated with drug-induced attenuation of enhanced depression-like behavior in rats bred for high anxiety. Biol Psychiatry 61: 782-796.

Muigg P, Scheiber S, Salchner P, Bunck M, Landgraf R, Singewald N (2009). Differential stress-induced neuronal activation patterns in mouse lines selectively bred for high, normal or low anxiety. PLoS One 4: e5346.

Nauta WJ, Domesick VB (1984). Afferent and efferent relationships of the basal ganglia. Ciba Found Symp 107: 3-29.

Nowak LG, Bullier J (1998a). Axons, but not cell bodies, are activated by electrical stimulation in cortical gray matter. I. Evidence from chronaxie measurements. Exp Brain Res 118: 477-488.

Nowak LG, Bullier J (1998b). Axons, but not cell bodies, are activated by electrical stimulation in cortical gray matter. II. Evidence from selective inactivation of cell bodies and axon initial segments. Exp Brain Res 118: 489-500.

Parkinson JA, Olmstead MC, Burns LH, Robbins TW, Everitt BJ (1999). Dissociation in effects of lesions of the nucleus accumbens core and shell on appetitive pavlovian approach behavior and the potentiation of conditioned reinforcement and locomotor activity by D-amphetamine. J Neurosci 19: 2401-2411.

Rodriguez-Romaguera J, Do Monte FH, Quirk GJ (2012). Deep brain stimulation of the ventral striatum enhances extinction of conditioned fear. Proc Natl Acad Sci USA 109: 8764-8769.

Sah A, Schmuckermair C, Sartori SB, Gaburro S, Kandasamy M, Irschick $\mathrm{R}$ et al (2012). Anxiety- rather than depression-like behavior is associated with adult neurogenesis in a female mouse model of higher trait anxiety- and comorbid depression-like behavior. Transl Psychiatry 2: e171.

Salomé N, Salchner P, Viltart O, Sequeira H, Wigger A, Landgraf R et al (2004). Neurobiological correlates of high (HAB) versus low anxiety-related behavior (LAB): differential Fos expression in HAB and LAB rats. Biol Psychiatry 55: 715-723.

Samuels BA, Hen R (2011). Neurogenesis and affective disorders. Eur J Neurosci 33: 1152-1159.

Sartori SB, Hauschild M, Bunck M, Gaburro S, Landgraf R, Singewald N (2011a). Enhanced fear expression in a psychopathological mouse model of trait anxiety: pharmacological interventions. PLoS One 6: e16849.

Sartori SB, Landgraf R, Singewald N (2011b). The clinical implications of mouse models of enhanced anxiety. Fut Neurol 6: $531-571$.

Sartori SB, Whittle N, Hetzenauer A, Singewald N (2012). Magnesium deficiency induces anxiety and HPA axis dysregulation: modulation by therapeutic drug treatment. Neuropharmacology 62: 304-312.

Sartorius A, Mahlstedt MM, Vollmayr B, Henn FA, Ende G (2007). Elevated spectroscopic glutamate/gamma-amino butyric acid in rats bred for learned helplessness. NeuroReport 18: 1469-1473.

Schermer M (2011). Ethical issues in deep brain stimulation. Front Integr Neurosci 5: 17.

Schlaepfer TE, Cohen MX, Frick C, Kosel M, Brodesser D, Axmacher $\mathrm{N}$ et al (2008). Deep brain stimulation to reward circuitry alleviates anhedonia in refractory major depression. Neuropsychopharmacology 33: 368-377.

Singewald N (2007). Altered brain activity processing in highanxiety rodents revealed by challenge paradigms and functional mapping. Neurosci Biobehav Rev 31: 18-40.

Stone SS, Teixeira CM, Devito LM, Zaslavsky K, Josselyn SA, Lozano AM et al (2011). Stimulation of entorhinal cortex promotes adult neurogenesis and facilitates spatial memory. J Neurosci 31: 13469-13484.

Tan SK, Hartung H, Visser-Vandewalle V, Steinbusch HW, Temel $\mathrm{Y}$, Sharp $\mathrm{T}$ (2012). A combined in vivo neurochemical and electrophysiological analysis of the effect of high-frequency stimulation of the subthalamic nucleus on 5-HT transmission. Exp Neurol 233: 145-153.

Toda H, Hamani C, Fawcett AP, Hutchison WD, Lozano AM (2008). The regulation of adult rodent hippocampal neurogenesis by deep brain stimulation. J Neurosurg 108: 132-138.

Tremblay LK, Naranjo CA, Graham SJ, Herrmann N, Mayberg HS, Hevenor $S$ et al (2005). Functional neuroanatomical substrates of 
altered reward processing in major depressive disorder revealed by a dopaminergic probe. Arch Gen Psychiatry 62: 1228-1236.

Trivedi MH, Rush AJ, Wisniewski SR, Nierenberg AA, Warden D, Ritz L et al (2006). Evaluation of outcomes with citalopram for depression using measurement-based care in STAR ${ }^{*} \mathrm{D}$ : implications for clinical practice. Am J Psychiatry 163: 28-40.

van der Plasse G, Schrama R, van Seters SP, Vanderschuren LJ, Westenberg HG (2012). Deep brain stimulation reveals a dissociation of consummatory and motivated behaviour in the medial and lateral nucleus accumbens shell of the rat. PLoS One 7: e33455.

van Kuyck K, Gabriels L, Cosyns P, Arckens L, Sturm V, Rasmussen $S$ et al (2007). Behavioural and physiological effects of electrical stimulation in the nucleus accumbens: a review. Acta Neurochir Suppl 97(Part 2): 375-391.

Vieta E, Colom F (2011). Therapeutic options in treatmentresistant depression. Ann Med 43: 512-530.

Vitek JL (2002). Mechanisms of deep brain stimulation: excitation or inhibition. Movem Disord 17(Suppl 3): S69-S72.

Wang Y, Yang F, Liu YF, Gao F, Jiang W (2011). Acetylsalicylic acid as an augmentation agent in fluoxetine treatment resistant depressive rats. Neurosci Lett 499: 74-79.

Whittle N, Li L, Chen WQ, Yang JW, Sartori SB, Lubec G et al (2011). Changes in brain protein expression are linked to magnesium restriction-induced depression-like behavior. Amino Acids 40: 1231-1248.

Winter C, Vollmayr B, Djodari-Irani A, Klein J, Sartorius A (2011). Pharmacological inhibition of the lateral habenula improves depressive-like behavior in an animal model of treatment resistant depression. Behav Brain Res 216: 463-465.

Wittchen HU, Jacobi F, Rehm J, Gustavsson A, Svensson M, Jonsson B et al (2011). The size and burden of mental disorders and other disorders of the brain in Europe 2010. Eur Neuropsychopharmacol 21: 655-679.

Yeragani VK, Pohl R, Mallavarapu M, Balon R (2003). Approximate entropy of symptoms of mood: an effective technique to quantify regularity of mood. Bipolar Disord 5: 279-286.

Zangenehpour S, Chaudhuri A (2002). Differential induction and decay curves of c-fos and zif268 revealed through dual activity maps. Brain Res Mol Brain Res 109: 221-225.

Zhao C, Deng W, Gage FH (2008). Mechanisms and functional implications of adult neurogenesis. Cell 132: 645-660.

(c) (1) (-) $\Theta$ This work is licensed under a Creative Commons Attribution-NonCommercial-NoDerivs 3.0 Unported License. To view a copy of this license, visit http:// creativecommons.org/licenses/by-nc-nd/3.0/

Supplementary Information accompanies the paper on the Neuropsychopharmacology website (http://www.nature.com/npp) 